\title{
A narrative review of advanced ventilator modes in the pediatric intensive care unit
}

\author{
Andrew G. Miller ${ }^{1,2}$, Renee M. Bartle ${ }^{1,2}$, Alexandra Feldman ${ }^{1,3}$, Palen Mallory ${ }^{1,3}$, Edith Reyes ${ }^{1,3}$, \\ Briana Scott ${ }^{1,3}$, Alexandre T. Rotta ${ }^{1,3}$ \\ ${ }^{1}$ Duke University Medical Center, Durham, NC, USA; ${ }^{2}$ Respiratory Care Services, Duke University Medical Center, Durham, NC, USA; ${ }^{3}$ Division \\ of Pediatric Critical Care Medicine, Duke University Medical Center, Durham, NC, USA \\ Contributions: (I) Conception and design: AG Miller, AT Rotta; (II) Administrative support: None; (III) Provision of study materials or patients: \\ None; (IV) Collection and assembly of data: None; (V) Data analysis and interpretation: None; (VI) Manuscript writing: All authors; (VII) Final \\ approval of manuscript: All authors. \\ Correspondence to: Andrew G. Miller, MSc, RRT-ACCS, RRT-NPS. Duke University Medical Center, Respiratory Care Services, 2301 Erwin Rd, \\ Durham, NC 27710, USA. Email: Andrew.g.miller@duke.edu.
}

\begin{abstract}
Respiratory failure is a common reason for pediatric intensive care unit admission. The vast majority of children requiring mechanical ventilation can be supported with conventional mechanical ventilation (CMV) but certain cases with refractory hypoxemia or hypercapnia may require more advanced modes of ventilation. This paper discusses what we have learned about the use of advanced ventilator modes [e.g., high-frequency oscillatory ventilation (HFOV), high-frequency percussive ventilation (HFPV), high-frequency jet ventilation (HFJV) airway pressure release ventilation (APRV), and neurally adjusted ventilatory assist (NAVA)] from clinical, animal, and bench studies. The evidence supporting advanced ventilator modes is weak and consists of largely of single center case series, although a few RCTs have been performed. Animal and bench models illustrate the complexities of different modes and the challenges of applying these clinically. Some modes are proprietary to certain ventilators, are expensive, or may only be available at well-resourced centers. Future efforts should include large, multicenter observational, interventional, or adaptive design trials of different rescue modes (e.g., PROSpect trial), evaluate their use during ECMO, and should incorporate assessments through volumetric capnography, electric impedance tomography, and transpulmonary pressure measurements, along with precise reporting of ventilator parameters and physiologic variables.
\end{abstract}

Keywords: High-frequency ventilation; mechanical ventilation; pediatric; airway-pressure release ventilation; neurally adjusted ventilatory assist (NAVA)

Submitted Oct 13, 2020. Accepted for publication Nov 26, 2020.

doi: $10.21037 / \mathrm{tp}-20-332$

View this article at: http://dx.doi.org/10.21037/tp-20-332

\section{Introduction}

Respiratory failure is a common reason for pediatric intensive care unit (PICU) admission. The vast majority of children requiring mechanical ventilation can be supported with conventional mechanical ventilation $(\mathrm{CMV})$ but certain cases with refractory hypoxemia or hypercapnia may require more advanced modes of ventilation; although high-level evidence supporting these modes is limited. For the purposes of this review, advanced ventilator modes include high-frequency oscillatory ventilation (HFOV), high-frequency percussive ventilation (HFPV), highfrequency jet ventilation (HFJV) airway pressure release ventilation (APRV), and neurally adjusted ventilatory assist (NAVA). Adaptive Support Ventilation was considered for inclusion; however, we determined the mode was an advanced servo regulated mode similar to pressureregulated pressure control. Proportional assist ventilation 
$(\mathrm{PAV}+)$ was also considered for inclusion but we were unable to identify any studies germane to the PICU; $\mathrm{PAV}+$ has been found to be feasible and safe in premature neonates (1). We present the following narrative review in accordance with the Narrative Review reporting checklist (available at http://dx.doi.org/10.21037/tp-20-332) on the use of advanced ventilator modes in pediatric critical care and discuss evidence generated from clinical, animal, and bench studies.

\section{Methods}

We searched MEDLINE for studies done in pediatric patients for clinical studies and all bench and animal studies potentially relevant to pediatric critical care, excluding studies of neonates or premature animal models. Adult animal and bench models were included as they are applicable to older children. All studies published prior to October 1, 2020 were included unless specifically stated in the individual sections. Searches were supplemented by reviewing references within individual papers. We reviewed primary sources for pediatric studies and relied on systematic reviews of adult data. The keywords used for the search included: high-frequency ventilation, HFOV, HFPV, HFJV, airway-pressure release ventilation, and NAVA. Boolean logic was used to limit the search to children and identify animal studies.

\section{Principles and physiology of high-frequency ventilation}

During normal spontaneous breathing and CMV, gas movement occurs due to convection and molecular diffusion. Convection is the bulk flow of gas through the conducting airways [anatomical dead space (VD)] as the result of a pressure gradient caused by diaphragm contraction during normal breathing or from positive pressure ventilation. Diffusion is the movement of gas molecules down a concentration gradient in the distal parts of the airway and alveoli. Based on these mechanisms, alveolar ventilation (VA) theoretically can only occur if the tidal volume (VT) exceeds VD.

High-frequency ventilation uses a VT that often is lower than VD but alveolar ventilation still occurs. The precise mechanisms of gas transport during highfrequency ventilation remain unclear and vary depending on the high frequency technique employed, yet six distinct gas transport mechanisms have been proposed (Figure 1).
These are bulk gas flow, pendelluft, cardiogenic mixing, asymmetric velocity profiles, Taylor dispersion, and molecular diffusion (2-7). The details of gas exchange mechanisms during high-frequency ventilation is beyond the scope of this article and have been reviewed elsewhere (2-7).

\section{HFOV}

HFOV is a technique that employs respiratory rates between 5 and $15 \mathrm{~Hz}$ (300 to 900 breaths per minute), and a VT (approximately $1-3 \mathrm{~mL} / \mathrm{kg}$ ) that often are $\leq \mathrm{VD}$. During HFOV, the ventilator circuit is pressurized by the combination of bias flow (gas entering the circuit) and leakage through a low pass filter or exhalation valve (gas leaving the circuit) that determines the mean airway pressure (mPaw). Gas is then displaced towards and away from the patient through a piston or a magnetically controlled piston-diaphragm system.

HFOV is unique in that both inspiration and exhalation are active processes. During HFOV, oxygenation and ventilation are relatively independent, although overdistension or low functional residual capacity may affect carbon dioxide $\left(\mathrm{CO}_{2}\right)$ clearance. Oxygenation is controlled by the fraction of inspired oxygen $\left(\mathrm{FiO}_{2}\right)$ and mPaw while ventilation is dependent on VT (amplitude, controlled by the power setting) and frequency (in $\mathrm{Hz}$ ). Ventilation is inversely proportional to frequency; lower frequencies result in higher VT and increased ventilation. VT increases or decreases in the same direction as amplitude. Pressure amplitude in the more distal airways is significantly attenuated during HFOV, thus mechanical strain and stress on the alveoli are minimized. HFOV has been purported as a form of lung protective ventilation that minimizes volutrauma, atelectrauma, and biotrauma (8). A detailed description of HFOV physiology, gas transport mechanisms, and settings for various clinical conditions is beyond the scope of this article and has been discussed elsewhere $(3,9)$.

\section{Clinical studies}

HFOV has been well studied in adults with ARDS (10-16), but randomized controlled trials (RCTs) in pediatric ARDS (PARDS) are sparse. A meta-analysis performed prior to two large RCTs - OSCAR (13) and OSCILLATE (14)—concluded HFOV might improve survival and is unlikely to cause harm, but the analysis included studies where the control groups did not receive lung-protective ventilation (17). While the OSCAR 


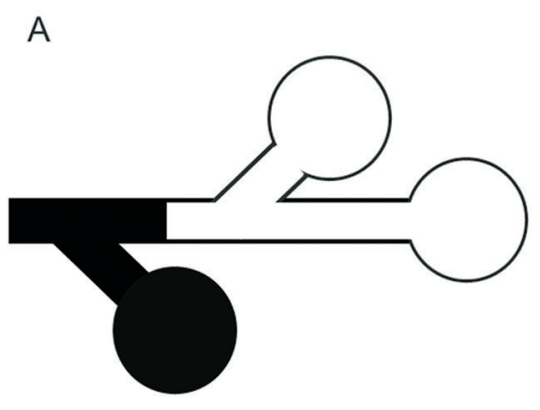

\section{B}

\section{1}
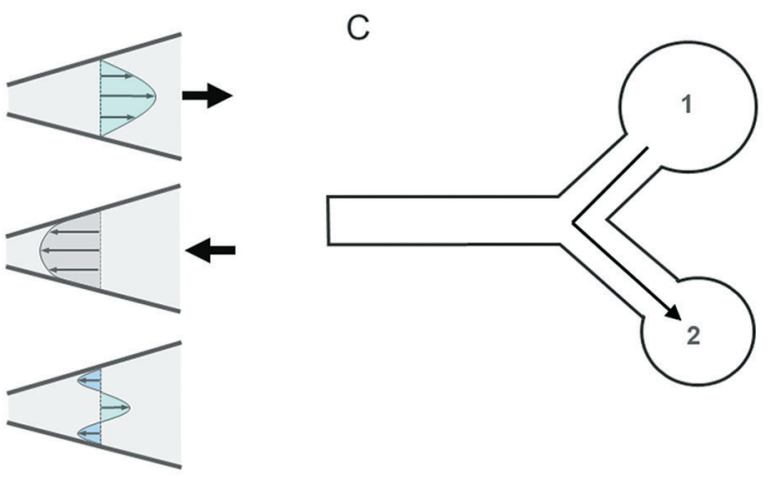

3

D

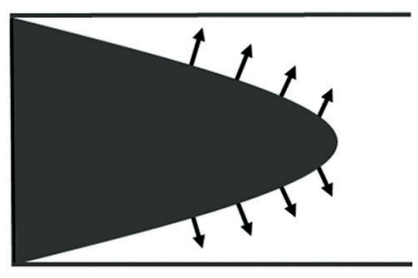

E

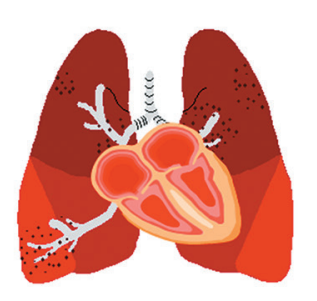

$\mathrm{F}$

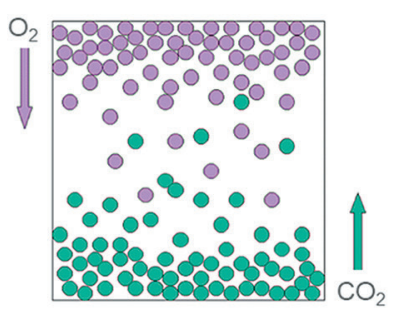

Figure 1 Mechanisms of gas exchange during high-frequency ventilation. (A) Direct ventilation by bulk gas movement reaching the most proximal alveoli. (B) Streaming of gas flow in a diverging conduit: 1, inspiration; 2, active exhalation; 3 , net effect depicting fresh gas being transported through the center of the airway and carbon dioxide-rich gas through the periphery of the airway. (C) Pendelluft between two adjacent alveoli of different time constants: a fast alveolus [1] emptying into a slow alveolus [2]. (D) Radial mixing from diffusion during augmented (Taylor) dispersion. (E) Cardiogenic mixing. (F) Molecular diffusion along concentration gradients.

trial showed no benefit of HFOV over protective CMV, the OSCILLATE trial found that HFOV increased mortality, possibly due to the inclusion of a large number of patients with sepsis and hemodynamic instability. Subsequent metaanalyses that included OSCAR and OSCILLATE did not demonstrated a survival benefit for HFOV, especially when excluding studies in which the control group did not receive lung-protective ventilation (18-20).

\section{Pediatric studies}

An early report demonstrated that HFOV using a high mean lung volume strategy was safe and effective in seven children with diffuse alveolar disease and severe respiratory failure (21). HFOV was also effective as a rescue modality in a cohort of twelve children with severe respiratory failure refractory to CMV (22). The first RCT comparing HFOV to $\mathrm{CMV}$ in 70 children with severe hypoxemic respiratory failure showed that HFOV improved oxygenation and decreased the need for supplemental oxygen at 30 days, but did not decrease mortality (23). Another RCT involving 61 children $(\mathrm{HFOV}=37$ vs. $\mathrm{CMV}=24)$ with acute hypoxemic respiratory failure was stopped prematurely for lower than expected enrollment (11). Analysis of the available data did not demonstrate differences, but a post-hoc analysis suggested that HFOV might be beneficial in patients with an oxygenation index greater than 30 (11).

A recent retrospective observational study compared outcomes of HFOV to CMV using propensity score matching (24). This study included 9,177 patients from 98 hospitals in the Virtual PICU System database, and concluded that the application of HFOV (both early 
and late) was associated with increased mortality. These findings must be taken with caution, since the propensity score matching used in that study did not include clinically important variables, such as $\mathrm{FiO}_{2}$, airway pressures, and arterial blood gas measurements. Therefore, it is possible the subjects receiving HFOV represented a sicker cohort (24). A multicenter study of HFOV vs. CMV used propensity score matching to study 118 pairs of children with PARDS found HFOV was associated with increased mortality but no difference in ventilator-free days (25). In a secondary analysis of the RESTORE trial, propensity score matching found early application of HFOV was associated with longer duration of mechanical ventilation but did not affect mortality (26).

de Jager $e t a l$. recently described the feasibility of a physiologic, open-lung recruitment strategy of HFOV in 143 subjects treated in a single center (27). This strategy uses a starting frequency of $12 \mathrm{~Hz}$ for all subjects and uses incremental-decremental staircase adjustments to select the "optimal" mPaw on the deflation limb of pressurevolume curve (27). Ventilation is controlled by adjusting the frequency after maximizing the power (amplitude) setting (27). This is in contrast to prior HFOV strategies, which have used a fixed starting frequency based on the patient's size and controlled ventilation with changes in power (amplitude). The reported mortality for different PARDS severity was similar to the mortality reported in a large, multicenter, international point prevalence study (28). Importantly, this HFOV strategy is currently being employed in the ongoing PROSpect trial.

\section{Animal studies}

Relevant animal studies of HFOV were completed over two decades ago and demonstrated it to be superior to CMV for physiologic and pathobiologic outcomes (29-33). Although crucial in refining the HFOV strategies for translation into human trials, these early studies suffered from the limitation that the CMV groups did not receive lung protective ventilation with physiologic $(4-8 \mathrm{~mL} / \mathrm{kg}) \mathrm{VT}$ and adequate PEEP (29). Therefore, it was not surprising that HFOV performed better than non-protective CMV. When optimal HFOV was compared against optimal CMV, both modalities performed similarly, suggesting that a lung protective approach-accomplished through either CMV or HFOV-attenuates experimental lung injury regardless of the technique employed $(34,35)$.

\section{Conclusion and recommendations for clinical practice}

The Pediatric Acute Lung Injury Consensus Conference (PALICC) recommends that HFOV should be considered as an alternative ventilatory mode in patients with moderate-tosevere PARDS in whom plateau pressure exceeds $28 \mathrm{cmH}_{2} \mathrm{O}$, provided chest wall compliance is normal (36). When used, HFOV should be titrated to optimize lung volume through exploration of the potential for lung recruitment by a stepwise increase and decrease of the mPaw under continuous monitoring of the oxygenation and ventilation, along with hemodynamic parameters (36). Although the safety and feasibility of HFOV is well established in PARDS and is associated with improvement of shortterm physiologic endpoints, HFOV has not been shown to improve clinically meaningful outcomes, such as mortality or ventilator-free days. HFOV is a complex, nuanced mode of ventilation with a steep learning curve, so its use must be approached with respect even by those experienced its use. Until more definitive data are available, it is reasonable to continue to utilize HFOV as an option for the management of select patients with moderate-to-severe PARDS (37).

The question of whether HFOV has a definitive role in the management of PARDS can only be answered by a large multicenter RCT. The PROSpect trial comparing HFOV to CMV and prone positioning to supine in a twoby-two factorial adaptive design is currently ongoing, with a planned enrollment of 1,000 children with acute hypoxemic respiratory failure (38).

\section{HFPV}

HFPV is a pneumatically powered, time-cycled and pressure-limited ventilation form of mechanical ventilation used predominantly in inhalation injury, burns, and as a rescue mode for selected patients failing CMV. Highfrequency percussive breaths are superimposed upon a conventional pressure-controlled breath, usually in a $1: 1$ inspiratory to expiratory ratio with $10-30$ breaths per minute, depending on patient size. It can be used with other I:E ratios (39). Peak inspiratory pressure (PIP) and positive end-expiratory pressure (PEEP) are set; however, due to the Phasitron, both the PIP and PEEP "oscillate" around the set value, and the mean value for both PIP and PEEP are used (Figure 2). The percussive rate is set between 200 and 900 cycles per minute. Due to the unique mechanism of action, the lung is inflated in a controlled manner until the PIP is reached. Exhalation is passive and patients cannot 


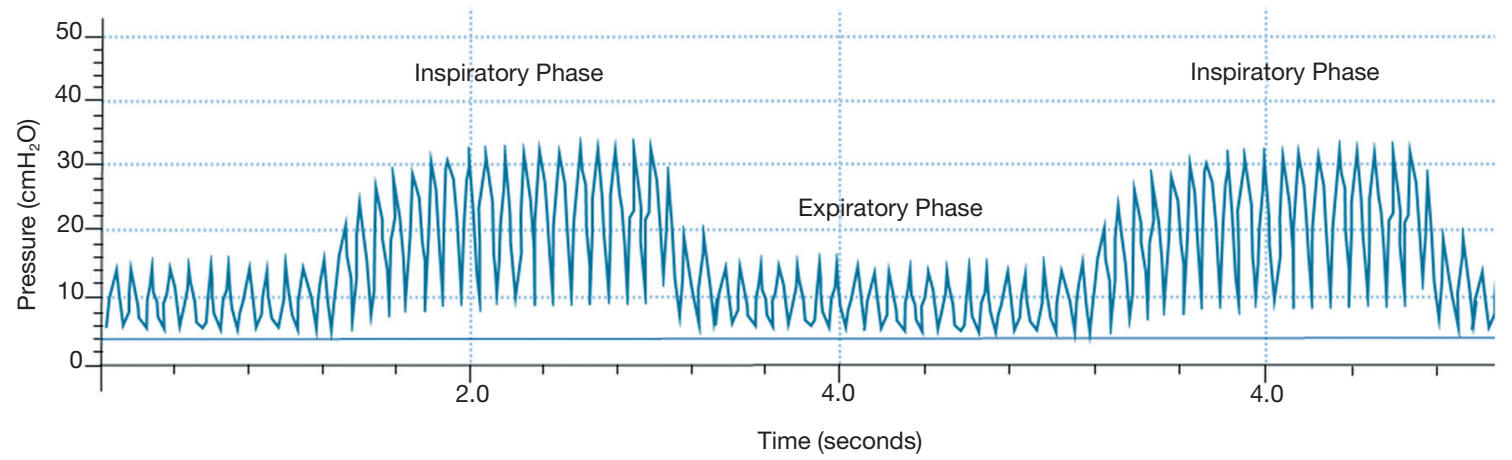

Figure 2 Graphic representation of high-frequency percussive ventilation (HFPV) pressure waveforms over time. Set peak inspiratory pressure (PIP) and positive end-expiratory pressure (PEEP) are the mean values during inspiratory and expiratory phases.

trigger the ventilator, although there is a reserve volume within the circuit with which patients can spontaneously inspire gas. We reviewed the literature over the past 15 years; earlier data have been discussed elsewhere (39).

\section{Clinical studies}

RCTs involving children are lacking and data are limited to case series/reports and retrospective studies (Table 1) (40-46). HFPV has been better studied in the adult burn population; however, case reports/series and retrospective studies comprise the majority of current data, with few RCTs and systematic reviews.

A systematic review of high frequency modalities as salvage therapy in adult and pediatric patients with smoke inhalation-associated acute lung injury concluded that HFPV may decrease mortality and pneumonia when compared to CMV, although the quality of evidence was low (47). A small before $(\mathrm{n}=22)$ and after $(\mathrm{n}=14)$ study found that HFPV use in pediatric extracorporeal life support (ECLS) was associated with more ECLS-free days, but not with improved survival or ventilator free days (48).

\section{Animal studies}

HFPV was evaluated against large VT CMV $(10 \mathrm{~mL} / \mathrm{kg})$ in a sheep burn/ARDS model and was found to increase survival without adverse hemodynamic effects (49). There were no differences in $\mathrm{P} / \mathrm{F}$ ratio, although $\mathrm{PaCO}_{2}$ was lower during HFPV at a lower PIP (49). In a sheep smoke/burn model (50), HFPV in conjunction with extracorporeal $\mathrm{CO}_{2}$ removal showed improved survival compared to HFPV or low-tidal volume ventilation. There were no differences in hemodynamics or bronchial obstruction, although HFPV alone had less bronchial obstruction than those treated with arterio-venous $\mathrm{CO}_{2}$ removal (50).

The effects of HFPV on nitrogen washout were studied in an ex-vivo model of adult porcine lungs with normal or low compliance using a HFPV-high [PIP $40 \mathrm{cmH}_{2} \mathrm{O}$ and continuous positive airway pressure (CPAP) $\left.20 \mathrm{cmH}_{2} \mathrm{O}\right]$ or HFPV-low (PIP $30 \mathrm{cmH}_{2} \mathrm{O}$ and CPAP $10 \mathrm{cmH}_{2} \mathrm{O}$ ) strategy (51). Compared to CMV, both HFPV strategies resulted in similar washout rates as CMV, but at a much lower VT and mean airway pressure (51).

In a rabbit model of gastric aspiration, HFPV improved respiratory mechanics, oxygenation, and markers of lung injury compared to non-protective $\mathrm{CMV}$, and performed similarly to protective CMV and HFOV (52). During HFPV, rabbits required higher doses of anesthetics to reach a predetermined surgical plane of anesthesia with no differences in gas exchange (53). While not confirmed in humans, this could suggest that patients receiving HFPV may require more sedation than those receiving CMV.

\section{Bench studies}

Bench models have evaluated VT delivery, the ability to measure accurate VT in clinical practice, humidification, nitrogen washout, and nitric oxide delivery during HFPV. Delivered VT and nitrogen washout during HFPV were affected by changes in elastance and resistance (54). When resistance was increased, the rise in VT was slower; when 
Table 1 Studies on high-frequency percussive ventilation in neonatal and pediatric patients

\begin{tabular}{|c|c|c|c|c|}
\hline $\begin{array}{l}\text { Author, year } \\
\text { published }\end{array}$ & Type of study & $\mathrm{N}$ & Pathology, if known & Findings of HFPV initiation \\
\hline $\begin{array}{l}\text { Rizkalla, } \\
2014\end{array}$ & Retrospective & 31 & $\begin{array}{l}\text { Acute respiratory failure } \\
\text { largely secondary to } \\
\text { infectious etiologies }\end{array}$ & $\begin{array}{l}\text { Improved gas exchange at lower PIP (median } 38 \text { vs. } 26 \mathrm{cmH}_{2} \mathrm{O} \text { ); } \\
\text { improved } \mathrm{OI} \text { and } \mathrm{P} / \mathrm{F} \text { as early as } 12 \text { hours later; decreased } \mathrm{PaCO}_{2} \\
\text { within } 6 \text { hours of initiation; initiation did not lead to increased } \\
\text { hemodynamic instability or more air leaks }\end{array}$ \\
\hline $\begin{array}{l}\text { Tawfik, } \\
2016\end{array}$ & Retrospective & 27 & $\begin{array}{l}\text { Acute respiratory failure, } \\
\text { multiple etiologies }\end{array}$ & $\begin{array}{l}\text { Most commonly documented reasons for HFPV: secretion } \\
\text { management }(52 \%) \text { and ventilation }(30 \%) \text {; improved oxygenation, } \\
\text { decreased } \mathrm{PaCO}_{2} \text { levels } 6 \text { hours after initiation (PIP }<30 \mathrm{cmH}_{2} \mathrm{O}, \mathrm{mPaw} \\
16 \pm 2.9) \text {; complications: hypotension requiring return to } \mathrm{CMV}(4 \%) \text {, } \\
\text { pneumothorax (4\%), and bronchoscopy for secretion removal }(15 \%)\end{array}$ \\
\hline $\begin{array}{l}\text { Paviotti, } \\
2014\end{array}$ & $\begin{array}{l}\text { Case } \\
\text { series }\end{array}$ & 6 & $\begin{array}{l}\text { Persistent pulmonary } \\
\text { hypertension of the } \\
\text { newborn (PPHN); severe } \\
\text { hypoxemic } \\
\text { respiratory failure }\end{array}$ & $\begin{array}{l}\text { Marked oxygenation improvement with a decrease in } \mathrm{OI}-\text { achieved } \\
\text { without an increase in mPaw and PIP; no change in } \mathrm{PaCO}_{2} \text { values, } \\
\text { although hypercarbia is rarely a complicating factor in } \mathrm{PPHN} \text {; } \\
\text { concluded HFPV could play a role in neonatal hypoxemic respiratory } \\
\text { failure unresponsive to CMV/HFOV and medical management, } \\
\text { especially in centers where ECMO is unavailable }\end{array}$ \\
\hline $\begin{array}{l}\text { Mabe, } \\
2007\end{array}$ & $\begin{array}{l}\text { Case } \\
\text { report }\end{array}$ & 1 & $\begin{array}{l}\text { Aspiration pneumonitis from } \\
\text { hydrocarbon inhalation }\end{array}$ & $\begin{array}{l}\text { Mobilization of large amounts of secretions } \\
\text { Improvement in oxygenation }\end{array}$ \\
\hline $\begin{array}{l}\text { Fitzgerald, } \\
2011\end{array}$ & $\begin{array}{l}\text { Case } \\
\text { report }\end{array}$ & 1 & $\begin{array}{l}\text { ARDS secondary to post } \\
\text { intubation tracheal injury with } \\
\text { severe air leak } \\
\text { syndrome on VV ECMO }\end{array}$ & $\begin{array}{l}\text { Prior to ECMO decannulation, marked improvement in secretion } \\
\text { clearance; complete expansion of bilateral lungs without disrupting } \\
\text { healing trachea }\end{array}$ \\
\hline $\begin{array}{l}\text { Claudet, } \\
2012\end{array}$ & $\begin{array}{l}\text { Case } \\
\text { report }\end{array}$ & 1 & $\begin{array}{l}\text { ARDS secondary to hydrogen } \\
\text { sulfide gas intoxication from } \\
\text { submersion in a manure tank }\end{array}$ & Recovery from respiratory failure \\
\hline
\end{tabular}

HFPV, high-frequency percussive ventilation; PIP, peak inspiratory pressure; CMV, conventional mechanical ventilation; mPaw, mean airway pressure; HFOV, high-frequency oscillatory ventilation.

elastance was increased, the VT reached a plateau quickly, resulting in a longer "plateau" during inspiration. The measured VT total (or total gas delivered during each inspiratory phase) ranged from 710 to $1,820 \mathrm{~mL}$, which is outside the lung protective range, although 300 to $848 \mathrm{~mL}$ was exhaled during the inspiratory phase due to passive exhalation following percussive breaths. Changes in elastance and resistance also resulted in changes in the delivered mPaw and PIP with both increasing when elastance and resistance increased. The VT delivered during the percussive breaths was more effected by changes in resistance than in elastance (54).

During HFPV, endotracheal tube cuff deflation resulted in a decrease in proximal airway pressure (Pvent), measured mPaw, and $\mathrm{FiO}_{2}$ at the simulated carina (55). The lower
$\mathrm{FiO}_{2}$ was likely due to increased entrainment of ambient air. Pvent was equal to the mPaw at the carina when the cuff was inflated (55). Increasing the percussive rate resulted in decreased VT but no change in the delta pressure with the cuff deflated (56). A study of airway humidification during HFPV found none of the humidification systems tested provided optimal humidity (57).

Gas distribution in a two-compartment lung model with varying elastance and resistance levels demonstrated VT delivery was affected by changes in lung mechanics (58). Nitrogen washout was more efficient at a lower mPaw during HFPV. Despite similar settings at the airway, HFPV was found to deliver $55 \%$ of the mPaw compared to PCV (58). Delivered VT can be measured accurately in real time during HFPV with external or portable monitors $(59,60)$. 
Elastance and resistance can also be estimated through an external monitor during HFPV with acceptable accuracy (61). It is not possible to precisely deliver inhaled nitric oxide during HFPV (62).

\section{Conclusion and recommendations for clinical practice}

HFPV has a role in the treatment of patients with smoke inhalation or burns. Its use in children and neonates has been shown to improve gas exchange without the need for higher airway pressure. HFPV is purported to improve secretion clearance, yet this has not been objectively demonstrated in children. Bench studies have shown that VT delivery is outside of the currently acceptable lungprotective range; although studies have shown conflicting results, likely due to how individual studies defined VT. Animal and bench models reveal complex cardiopulmonary interactions and further research is needed to elucidate what patient populations may benefit from HFPV. Future studies should attempt to include transpulmonary pressure monitoring, VT, and electric impedance tomography to evaluate the effect of HFPV on lung volumes.

\section{HFJV}

HFJV achieves ventilation through delivery of high-velocity gas using a solenoid activated pinch valve. This results in a pulsating stream of gas at a rate between 240 and 660 cycles per minute and an inspiratory time of 0.02 to $0.034 \mathrm{~s}$ (Figure 3). The resulting PIP is attenuated down the respiratory system and theoretically provides lung protective ventilation $(63,64)$. HFJV most often is utilized in premature infants or within neonatal intensive care units (NICUs) $(65,66)$. HFJV requires the use of both a jet ventilator and a conventional ventilator, the later used to provide PEEP and periodic recruitment or "sigh" breaths. The CMV rate is usually set between and 0 and 5 breaths per minute and the PIP is set below the HFJV PIP to avoid interruption of jet ventilation during CMV breaths. The use of HFJV in the PICU has been limited to small, single center case series and one outdated RCT (67-69).

\section{Recent clinical studies of HFFV in the PICU}

The use of HFJV in 35 infants (median 2.9 months and $5.2 \mathrm{~kg}$ ) with acute respiratory failure from multiple etiologies in a quaternary PICU was recently reported (67). HFJV improved $\mathrm{CO}_{2}$ clearance but had no effect on oxygenation.

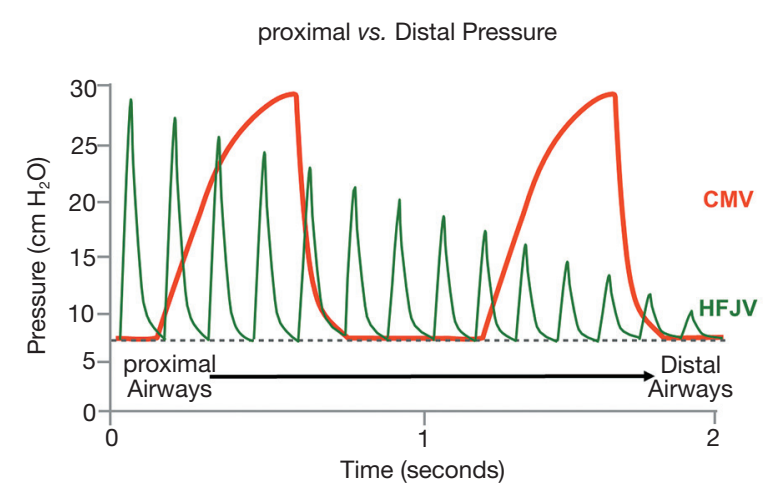

Figure 3 Graphic representation of proximal versus distal pressure during high-frequency jet ventilation (HFJV) compared to conventional mechanical ventilation (CMV). As the HFJV pulses move down the airway, there the pressure amplitude is attenuated, unlike CMV (courtesy of Evan Richards, RR).

HFJV failure was common, with $29 \%$ of subjects failing within $4-6 \mathrm{~h}$ post initiation and $51 \%$ making a successful transition from HFJV back to CMV. Initial HFJV PIP was $46 \mathrm{cmH}_{2} \mathrm{O}$ with a rate of 360 breaths per minute and mPaw of $14 \mathrm{cmH}_{2} \mathrm{O}$. ECMO was required for $26 \%$ of subjects and the overall survival was $74 \%$ (67).

HFJV was evaluated in a case series of 12 infants (1.7 to $14.2 \mathrm{~kg}$ ) with respiratory syncytial virus (RSV) failing CMV (68). HFJV was initiated primarily due to hypercapnia although $11 / 12$ patients also met PARDS criteria. The overall survival rate was $91 \%$. The mean partial pressure of $\mathrm{CO}_{2}\left(\mathrm{PaCO}_{2}\right)$ prior to HFJV decreased by nine $\mathrm{mmHg}$ after 24 hours; there was no significant change in oxygenation index (68). Importantly, the HFJV settings used, initiation criteria or detailed data prior to HFJV initiation were not reported.

The use of HFJV in 25 infants with congenital diaphragmatic hernia resulted in significant improvement in $\mathrm{pH}$ with a decrease in $\mathrm{PaCO}_{2}$ (70). The study reported general ventilation guidelines in which the $\mathrm{mPaw}$ was $<12 \mathrm{cmH}_{2} \mathrm{O}, \mathrm{PIP} \leq 25 \mathrm{cmH}_{2} \mathrm{O}$, mild-moderate permissive hypercapnia ( $\mathrm{pH}>7.25$ ) and target $\mathrm{SpO}_{2} \geq 85 \%$ but not did not report the specific settings used. Mortality rate was 64\% (70). Importantly, congenital diaphragmatic hernia may be managed in both NICUs and PICUs, depending on the center (71). HFJV with heliox as the driving gas was used in an infant with significant barotrauma and hypercapnia despite HFJV. The addition of heliox resulted in improved $\mathrm{PaCO}_{2}$ levels (72). 


\section{Clinical studies published before 2000}

Acute hypoxemic respiratory failure

Smith et al. (69) evaluated HFJV in 29 patients with PARDS (mean 1.0 years) and air leak syndrome. Prior to HFJV, PIP was $48 \mathrm{cmH}_{2} \mathrm{O}$ during $\mathrm{CMV}$ and $\mathrm{PaCO}_{2}$ was $45 \mathrm{mmHg}$. The survival rate was $69 \%$ (69). This study predates the wide-spread adoption of lung-protective ventilation and suggest HFJV may have a role in managing air-leak syndrome.

\section{Post cardiac surgery}

Several studies have evaluated the effect of HFJV on gas exchange and hemodynamics in infants and children with congenital heart disease. These have been small, single center studies with limited applicability in current PICUs.

HFJV was used in nine patients (mean age 9 months) after congenital heart surgery who met pulmonary criteria for ECMO, predominantly due to pulmonary hypertension (73). Ventilation and oxygenation improved during HFJV with similar PIP and mPaw as during CMV with stable hemodynamics. ECMO was avoided in all but one patient. The mortality rate was $33 \%$ and one patient developed a pneumothorax (73). HFJV was used in 13 patients (mean age 3.9 years, mean weight $13.9 \mathrm{~kg}$ ) after the Fontan operation (74). There were no differences in $\mathrm{PaCO}_{2}$ before, during or after HFJV but adequate support was achieved at a lower mPaw $\left(9.2 v s .4 .6 \mathrm{cmH}_{2} \mathrm{O}\right)$ with overall improved hemodynamics and cardiac index (74). Current management after the Fontan procedure is early extubation and avoidance of high intrathoracic pressures; it is unclear if HFJV still has a role in the management of children post Fontan as current devices may not be able to effectively ventilate larger children.

When HFJV was used in six infants weighing 2.4 to $5.7 \mathrm{~kg}$ post cardiac surgery, ventilation was achieved with lower PIP, significantly lower tracheal pressure (24 vs. $14 \mathrm{cmH}_{2} \mathrm{O}$ ) compared to $\mathrm{CMV}$, with no change in measured hemodynamic parameters (75). A similar study evaluated the effect of HFJV on hemodynamics of six infants post cardiac surgery and demonstrated a significant decrease in PIP from 25 to $11 \mathrm{cmH}_{2} \mathrm{O}$ and reduction in $\mathrm{mPaw}$ from 7 to $5 \mathrm{cmH}_{2} \mathrm{O}$, although this was likely related to a decrease in set PEEP. There was no relationship between HFJV and cardiac index, although in patients with low cardiac index, HFJV resulted in a $33 \%$ increase. There were no other differences in hemodynamic measurements (76).

\section{Animal studies of $\mathrm{HFFV}$}

HFJV has been studied in various animal models. Airway pressures and gas exchange were compared between CMV, $\mathrm{HFJV}$, and HFOV in 12 pigs weighing between 10 and $16 \mathrm{~kg}$ (77). HFJV resulted in lower $\mathrm{PaCO}_{2}$, higher $\mathrm{pH}$, and higher cardiac index with a lower mPaw compared to both CMV and HFOV. Importantly, this study found that the mPaw measured at the proximal airway and the trachea were nearly identical in contrast to a prior study in which tracheal pressure was significantly lower (75). This study examined HFJV in a configuration that may not be used in clinical practice in PICUs and the CMV strategy was not protective. A study of rabbits concluded that HFOV and HFJV cannot be compared on the basis of mPaw and demonstrated that mPaw accurately estimated mean alveolar pressure during HFJV (78). A study comparing $\mathrm{HFJV}$ and $\mathrm{HFOV}$ in cats with a mean weight of $4.5 \mathrm{~kg}$ showed that HFJV resulted in lower $\mathrm{PaCO}_{2}$ and higher $\mathrm{pH}$ at similar airway pressures but no change in oxygenation (79). Transition from HFJV to HFOV in this study resulted in acidosis, increased pulmonary artery pressure, increased PVR, and a decreased cardiac output (79).

\section{Bench studies}

Aerosol delivery during HFJV using magnetic resonance imaging of a phantom lung was lower in comparison to that during HFOV, and both were lower compared to CMV (80). Importantly, this study utilized the MiniHeart nebulizer driven by $2 \mathrm{~L} / \mathrm{min}$ of flow within the inspiratory limb of the conventional ventilator circuit. A mathematical equation to predict what PEEP needs to be set to match the mPaw when transitioning between HFJV and HFOV suggested that mPaw should be increased by 4 to $6 \mathrm{cmH}_{2} \mathrm{O}$ when initiating HFJV (81).

\section{Conclusion and recommendations for clinical practice}

Data evaluating HFJV in the PICU are limited to small, single center case series, outdated RCTs or physiologic studies without control groups. HFJV may have a role in refractory hypercapnia in children with viral bronchiolitis, in air leak syndrome, and post cardiac surgery to improve hemodynamics, although the impact on more relevant outcomes requires further investigation. 

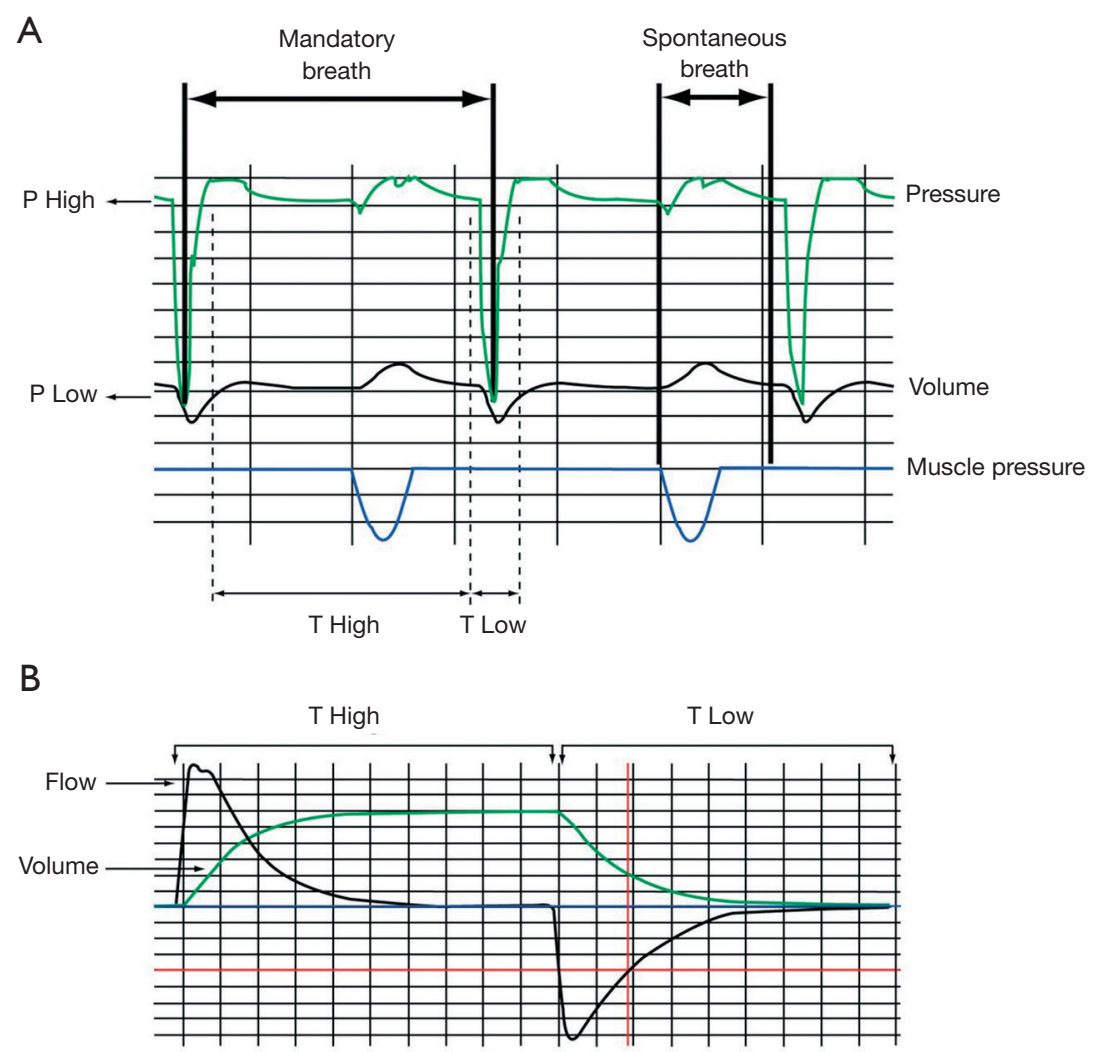

Figure 4 Pressure (green) and volume (black) over time curve in airway pressure release ventilation (APRV). Shown in the figure: 2 full mandatory breaths (not triggered by muscle effort), and 2 full spontaneous breaths (triggered by muscle effort, in blue) on the top of the mandatory ones. Muscle pressure (blue): the long arrow represents the $\mathrm{T}$ high, and the short arrow represents the $\mathrm{T}$ low of the mandatory breath. B: Flow (black) and volume (green) over time curve in APRV. T high is the start of the inspiratory flow to the start of expiratory flow, $\mathrm{T}$ low is the start of expiratory flow to the beginning of the next inspiratory flow. The 2 red intersecting lines are at $50 \%$ of the peak expiratory flow. [Reproduced with permission from: Daoud EG, Farag HL, Chatburn RL. Airway pressure release ventilation: what do we know? Respir Care. 2012;57(2):282-92.]

\section{APRV}

APRV is a time-cycled, pressure controlled, synchronized intermittent mandatory ventilation mode generally utilized with an inverse I:E ratio. It was first described in 1987 by Stock and Downs as a strategy to maintain lung volume, maximize alveolar recruitment, and avoid overdistension and collapse (82-86) (Figure 4). APRV maintains PIP (or P-high) with brief cyclical releases to enhance $\mathrm{CO}_{2}$ removal, with unrestricted spontaneous breathing during P-high. APRV has been used primarily as a rescue strategy in patients with ARDS or refractory hypoxemia $(84,87,88)$. Detailed descriptions of the intricacies of APRV are beyond the scope of this paper, but have been reviewed elsewhere $(84,86,89)$. A recent meta-analysis of adult studies found that APRV was associated with a higher number of ventilator free days, lower ICU length of stay, lower hospital mortality, and no significant adverse effects (90). These results need to be interpreted cautiously due to the low quality of the included trials and the fact that many control groups did not receive lung-protective ventilation. Importantly, what defines APRV and how it is used in clinical practice in adults varies widely $(91,92)$.

Proposed advantages of APRV include lung recruitment, improved oxygenation, unrestricted spontaneous breathing, improved hemodynamics, better V/Q matching, and reduction in sedative requirements. Disadvantages of APRV include difficulty of controlling VT, concern for atelectrauma during releases (especially in lung units with low compliance and resistance), and exposure to high 
transpulmonary pressure during spontaneous breathing at P-high. Current data evaluating APRV in children are limited to single center case series as a rescue mode for patients with refractory hypoxemia and one small, single center RCT (93-103).

\section{Prospective clinical studies in children}

A single center RCT comparing low VT CMV to APRV in PARDS was terminated early after enrolling 52 subjects due to a higher mortality rate $(54 \%$ vs. $27 \%)$ in the APRV group (98). There were significant differences in baseline characteristics between the groups, with the APRV group having lower baseline $\mathrm{P} / \mathrm{F}$ ratio and higher oxygenation index, although VT, P/F ratio and oxygenation index were similar $12 \mathrm{~h}$ post randomization and $\mathrm{mPaw}$ was approximately $2 \mathrm{cmH}_{2} \mathrm{O}$ higher in the APRV group throughout the study. After controlling for illness severity, APRV was associated with a risk ratio of 2.02 for mortality (98).

A prospective, crossover study comparing APRV to CMV in children after Tetralogy of Fallot, Glenn or Hemi-Fontan, or Fontan procedures found that APRV improved pulmonary blood flow, although $\mathrm{SvO}_{2}$ and other indexes of oxygenation were similar on both modes (100). APRV did not adversely affect hemodynamics using a P-high of $13-20 \mathrm{cmH}_{2} \mathrm{O}$ (100). An increase in pulmonary blood flow was observed only when patients in APRV were spontaneously breathing. There were no differences between groups in global hemodynamics measurements or gas exchange. This study revealed that during releases, the pleural pressure was negative despite a reasonably set T-low of $0.3-0.5$ seconds. In contrast, the end-expiratory transpulmonary pressure in the CMV group was at or above $0 \mathrm{cmH}_{2} \mathrm{O}$ throughout (100).

\section{Retrospective case series}

A retrospective analysis of 104 pediatric patients with ARDS, who were transitioned to either APRV or HFOV for refractory hypoxemia on CMV found that improvement in oxygenation after transition was associated with improved survival, independent of the rescue mode used (101). A similar study found that survival in immunocompromised patients with ARDS was significantly associated with improved oxygenation $24 \mathrm{~h}$ after transition to APRV or HFOV (102). A recent retrospective analysis of 30 pediatric patients with severe PARDS transitioned from CMV to APRV for refractory hypoxemia found that the $\mathrm{SpO}_{2} /$
$\mathrm{FiO}_{2}$ ratio increased from 132 to 165 , likely secondary to increased mPaw with a lower PIP, and a mortality rate of $17 \%$ (103). Previous small pediatric case series/case reports also observed improved oxygenation at lower peak airway pressure $(93,94,97,99)$ and no adverse hemodynamic effects $(95,96)$. A retrospective study comparing outcomes of rescue APRV $(n=22)$ or HFOV $(n=25)$ found no differences between the two groups (104). An important consideration during APRV is that the reduction in PIP may not result in a reduction of end-inspiratory transpulmonary pressure, as the patient's breathing effort will add to the P-high. Thus, a reduction of PIP during APRV may result in excessive transpulmonary pressure even when the P-high is within the lung-protective range, especially if tube compensation or pressure support are used.

\section{Animal models}

Multiple investigators have sought to examine the effects of APRV on lung microstrain and alveolar recruitment in animal models. In a porcine model of combined brain injury/ARDS, there were no differences in gas exchange or histopathology between APRV and an ARDSnet-based CMV strategy, although microdialysis trends suggested increased brain ischemia in the APRV group (105). APRV utilizing varying ratios of peak expiratory flow rate (PEFR) was compared to CMV with multiple levels of PEEP in a rat model of lung injury. During APRV, peak expiratory flow rate (PEFR) is terminated at a percentage of the peak expiratory flow, prior to complete exhalation, in order to create intrinsic PEEP as an alternative to extrinsically set PEEP. When this strategy is used, P-low is generally set to $0 \mathrm{cmH}_{2} \mathrm{O}(86,91)$. They found that both a PEEP greater than 16 and APRV with a PEFR targeted at $75 \%$ minimized microstrain, however APRV also improved alveolar recruitment (106). A similar study found a PEFR target of $75 \%$ during T-low resulted in the least alveolar microstrain (107). In other animal models, APRV has had a favorable effect on dynamic alveolar homogeneity (108) and has also led to improved mucous clearance (109). APRV was found to reduce inflammation and pulmonary edema in a rabbit model of ARDS (110).

Spontaneous breathing during APRV has been associated with improved gastrointestinal $(111,112)$, renal (113), and nervous system perfusion (114), and may reduce risk of lung injury (115). In a rat model, preemptive application of APRV to a normal lung prevented development of ARDSlike histopathology (116). In a porcine model of indirect 
lung injury, animals treated with APRV did not develop ARDS (117). It is important to note that the control groups in these studies did not receive lung-protective ventilation. APRV was compared to the ARDSnet protocol to examine whether ARDS could be prevented (118). The APRV group had preserved oxygenation with lung histology showing preserved lung architecture and less pulmonary edema. APRV was also shown to prevent ARDS in a rat model of hemorrhagic shock (119). Importantly, the vast majority of these animal studies originate from a single research group and most have used an ischemic-reperfusion sepsis model to induce extrapulmonary ARDS. The applicability of these results to primary pulmonary ARDS is limited. Lastly, these pre-clinical studies have yet to be translated to clinical practice.

\section{Bench models}

A case report demonstrated that VT during APRV ranged from 4 to $12 \mathrm{~mL} / \mathrm{kg}$ and the patient had CT scan consistent with ventilator induced lung injury. In a bench model, control of VT and auto-PEEP could not be achieved even in a passive model (120). In a study of APRV using a highfidelity simulator, auto-PEEP was found to be highly variable and resulted in unstable lung volumes (121). In a lung model, VT delivery during APRV was lower when compared to other modes (122). Spontaneous breathing during APRV results in variable VT and carries a risk of high VT delivery (123), yet aerosol deposition is increased compared to other modes (124). When compared to BiPAP with similar settings, APRV resulted in higher mPaw and higher total PEEP, and PEEP could not be predicted by lung mechanics (125). There is considerable variability in auto-PEEP during APRV among six commercially available ventilators (126).

\section{Conclusion and recommendations for clinical practice}

There is controversy on the choice of optimal settings, indication, and clinical efficacy of APRV. Current data have shown short-term improvements in oxygenation; however, this may not translate into improved patient outcomes and a pediatric RCT has suggested possible harm associated with APRV (98). Bench and animal studies have shown it to be a complex mode where VT and auto-PEEP cannot be easily controlled, even under ideal conditions. Importantly, its performance also varies across different ventilator platforms. High-quality, multi-center RCTs studies are needed to elucidate the role of APRV in PARDS. Other areas of interest requiring further study are the utility of APRV during ECMO and as a strategy to prevent the development of lung injury.

\section{NAVA}

NAVA is an advanced mode of mechanical ventilation in which breaths are synchronized to the electrical activity of the diaphragm (EAdi) using a proprietary ventilator and specialized gastric tube containing an array of electrodes positioned in the esophagus at the level of the diaphragm (127). The NAVA level is adjusted to provide positive pressure in proportion to the patient's effort, or EAdi, and synchronizes to the patient's neural respiratory drive (127). The EAdi signal is processed to provide the highest possible quality and is not artificially influenced by changes in lung volume, muscle length, chest wall configuration, intraabdominal pressure, and applied end-expiratory pressure (128-130) (Figure 5). NAVA is can be used in both invasive and noninvasive ventilation.

\section{Adult data}

A meta-analysis found NAVA improved ventilator synchrony but had no effect on patient outcomes such as length of stay, ventilator free days, or mortality (131). A recent RCT of critically ill adults expected to be mechanically ventilated for more than 72 hours found that NAVA resulted in four more ventilator free days, and 4.1 fewer days on mechanical ventilation, although there was no effect on mortality (132). A smaller RCT in patients at high risk of prolonged ventilation found NAVA to be associated with more ventilator free days and a decrease in mortality (133).

\section{Clinical use of NAVA in the PICU}

A recent meta-analysis 464 patients treated with NAVA or CMV showed NAVA to be associated with improved ventilator synchrony, lower PIP, and higher oxygen saturation (131). Crossover studies of NAVA in the PICU have consistently demonstrated improved patient-ventilator synchrony (134-139). An asynchrony rate between $12 \%$ and $73 \%$ has been described during CMV compared to zero to $20 \%$ during NAVA (140). NAVA has been shown to improve COMFORT scores $(138,141)$ and reduce sedation needs (142). An RCT of 170 subjects observed shorter ICU LOS using NAVA, although there was no difference in 


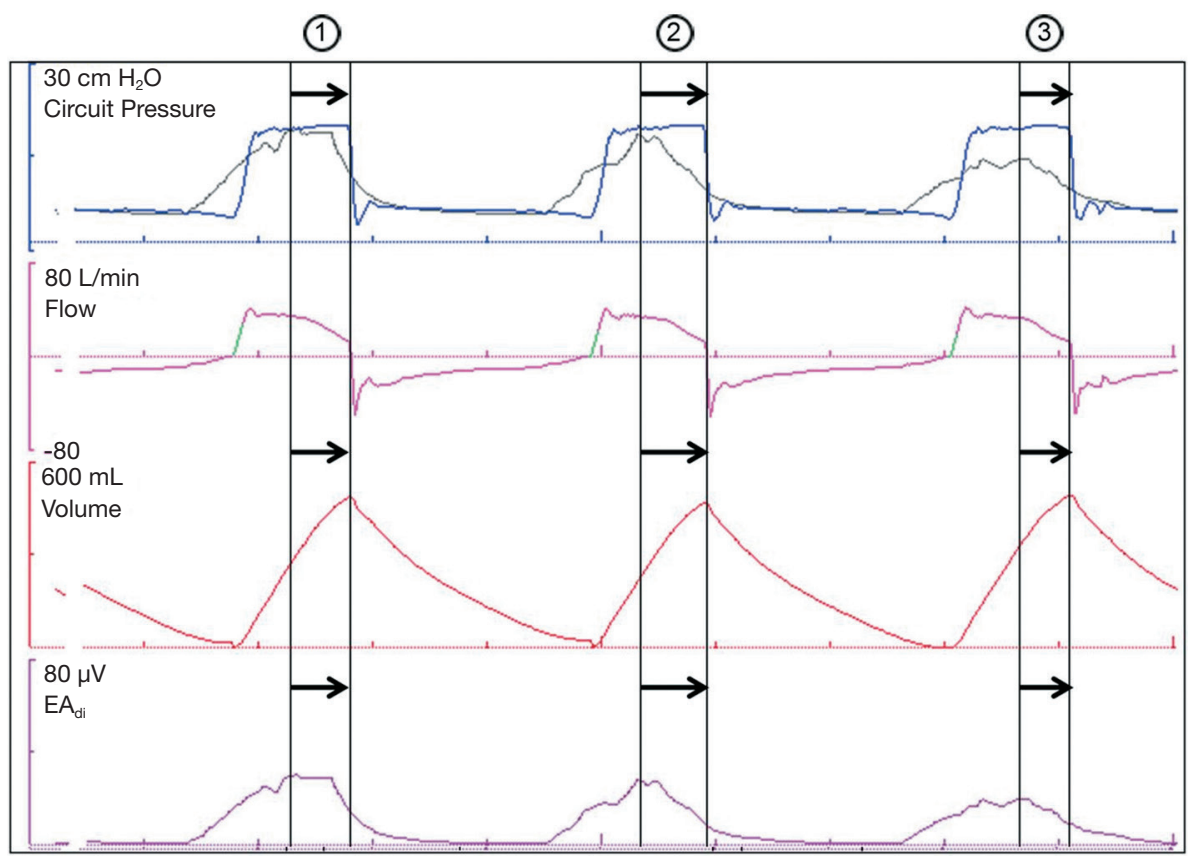

Figure 5 Pressure, flow, volume, and electrical activity of the diaphragm (EAdi) waveforms from a patient on pressure support ventilation, and the presumed pressure curve (grey) if the patient was on neurally adjusted ventilatory assist (NAVA), with a preset NAVA level not shown. Breath 3 demonstrates expiratory timing asynchrony: there is continued mechanical inflation after the start of the neural expiration, causing a delay between the neural expiration and the mechanical deflation. [Reproduced with permission from Verbrugghe W, Jorens PG. Neurally adjusted ventilatory assist: a ventilation tool or a ventilation toy? Respir Care. 2011;56(3):327-35.]

time on mechanical ventilation (142). In infants recovering from PARDS, NAVA showed improved synchrony, lower PIP, and a tendency toward higher VT (141). NAVAtriggered breaths have been shown to have less trigger delay and shorter system response time in infants with bronchiolitis (143). In another report of three children with bronchiolitis, NAVA was found to reduce PIP, improve patient-ventilator synchrony, and reduce $\mathrm{FiO}_{2}$ requirement (144). In a selected population of difficult to wean pediatric patients recovering from moderate PARDS, NAVA improved synchrony and resulted in better oxygenation compared to PSV (145).

\section{Congenital heart disease}

In children with congenital heart disease, NAVA has been shown to improve ventilator synchrony (134) with lower PIP and mPaw (146-148). NAVA had no effect on hemodynamics in the majority of patients post cardiac surgery (149). More recently, in a physiological cross-over study, NAVA was compared to PSV and PSV SIGH (PSV with 1 machine breath per minute) in hypoxemic infants after cardiac surgery. NAVA resulted in better patient-ventilator synchrony compared with pressure support but there was no difference in oxygenation and static compliance of the respiratory system (150).

In a small retrospective series, NAVA was used in six pediatric patients with severe respiratory failure on $\mathrm{VV}$ ECMO. NAVA was initiated when diaphragmatic electrical activity (EAdi) allowed for triggering. Proportionate to EAdi $(1.8-26 \mu \mathrm{V})$, initial PIP ranged from 21 to $34 \mathrm{cmH}_{2} \mathrm{O}$, and VT from 3 to $7 \mathrm{~mL} / \mathrm{kg}$. During weaning, PIP increased proportionally to EAdi increase $(5.2-41 \mu \mathrm{V})$, with VT ranging from 6.6 to $8.6 \mathrm{~mL} / \mathrm{kg}$. Improved synchrony during NAVA may help patients liberate from ECMO or help assess readiness for sweep gas trials (151).

\section{Animal models}

In a rabbit model, the use of NAVA was associated with less ventilator-induced lung injury, attenuated systemic inflammation, and preserved cardiac and kidney function (152). Other animal models have also demonstrated more efficient and synchronous ventilation $(153,154)$ with unloading of respiratory muscles without excessive VT and low mPaw (153). In animals recovering from lung 
injury, NAVA reduced asynchrony, trigger delay, and the pressure time product (155). In animals ventilated without PEEP after ALI, EAdi level was increased during the exhalation phase $(128,156)$. Application of PEEP in a step-wise fashion showed a dose-response reduction in tonic activity and re-institution of phasic breathing (156). In an anesthetized and spontaneously breathing rabbit model, adjusting pressure continuously in proportion to both inspiratory and expiratory EAdi showed a reduction in inspiratory effort compared to triggered NAVA (157). Recent experimental study demonstrates the use of EAdi to control negative pressure ventilation in small animals (158).

In an animal model of mild ARDS, NAVA showed that increasing PEEP reduced respiratory rate, atelectasis, recruitment/derecruitment, and breath size variability but increased VT and transpulmonary pressure (159). NAVA may be superior to PSV in preventing diaphragm injury during mechanical ventilation, and both NAVA and PSV were associated with less atrophy than CMV (160).

\section{Conclusion and recommendations for clinical practice}

NAVA can be safely applied in pediatric patients and is associated with improvements in ventilator synchrony and sedation requirements. These benefits are based on a small number of studies and have not translated into improved survival, ventilator-free days or time on mechanical ventilation. A large multicenter RCT to comparing NAVA and CMV in children is needed. Current evidence would suggest NAVA be applied in difficult to liberate patients or those in whom asynchrony has been observed or is highly suspected.

\section{Summary of advanced ventilator modes in the PICU and future directions for research}

The evidence supporting advanced ventilator modes is weak and consists largely of single center case series although some RCTs have been performed. This may have resulted in publication bias as centers with less favorable experiences with HFPV, HFJV, and APRV in particular, may not have published their results. Animal and bench models illustrate the complexities of different modes and the challenges of applying these clinically. Importantly, animal and bench models have often produced contradictory results, which underscores the need for additional research. Some modes are proprietary to certain ventilators, are expensive, or may only be available at well-resourced centers.

Future efforts should include large, multi-center observational, interventional, or adaptive design trials of different rescue modes (e.g., PROSpect trial), evaluate their use during ECMO, and should incorporate assessments through volumetric capnography, electric impedance tomography, and transpulmonary pressure measurements, along with precise reporting of ventilator parameters and physiologic variables.

\section{Acknowledgments}

Funding: None.

\section{Footnote}

Provenance and Peer Review: This article was commissioned by the Guest Editors (Jan Hau Lee, Vijay Srinivasan, and Debbie Long) for the series "Pediatric Critical Care" published in Translational Pediatrics. The article has undergone external peer review.

Reporting Checklist: The authors have completed the Narrative Review reporting checklist. Available at http:// dx.doi.org/10.21037/tp-20-332

Conflicts of Interest: All authors have completed the ICMJE uniform disclosure form (available at http://dx.doi. org/10.21037/tp-20-332). The series "Pediatric Critical Care" was commissioned by the editorial office without any funding or sponsorship. AGM reports personal fees from Ventec Life Systems, personal fees from American Association for Respiratory Care, outside the submitted work. Dr. ATR reports personal fees from Vapotherm, Inc, personal fees from Breas US, personal fees from Elsevier, outside the submitted work. The authors have no other conflicts of interest to declare.

Ethical Statement: The authors are accountable for all aspects of the work in ensuring that questions related to the accuracy or integrity of any part of the work are appropriately investigated and resolved.

Open Access Statement: This is an Open Access article distributed in accordance with the Creative Commons Attribution-NonCommercial-NoDerivs 4.0 International License (CC BY-NC-ND 4.0), which permits the noncommercial replication and distribution of the article with the strict proviso that no changes or edits are made and the original work is properly cited (including links to both the 
formal publication through the relevant DOI and the license). See: https://creativecommons.org/licenses/by-nc-nd/4.0/.

\section{References}

1. Schulze A, Rieger-Fackeldey E, Gerhardt T, et al. Randomized crossover comparison of proportional assist ventilation and patient-triggered ventilation in extremely low birth weight infants with evolving chronic lung disease. Neonatology 2007;92:1-7.

2. Horsfield K, Dart G, Olson DE, et al. Models of the human bronchial tree. J Appl Physiol 1971;31:207-17.

3. dos Santos CC, Slutsky AS. Overview of high-frequency ventilation modes, clinical rationale, and gas transport mechanisms. Respir Care Clin N Am 2001;7:549-75.

4. Slutsky AS. Gas mixing by cardiogenic oscillations: a theoretical quantitative analysis. J Appl Physiol Respir Environ Exerc Physiol 1981;51:1287-93.

5. Slutsky AS, Khoo MC, Brown R. Simulation of gas transport due to cardiogenic oscillations. J Appl Physiol (1985) 1985;58:1331-9.

6. Standiford TJ, Morganroth ML. High-frequency ventilation. Chest 1989;96:1380-9.

7. Taylor GO. The dispersion of matter in turbulent flow through a pipe. Proc R Soc [A]. 1954;223:446-8.

8. Imai Y, Slutsky AS. High-frequency oscillatory ventilation and ventilator-induced lung injury. Crit Care Med 2005;33:S129-34.

9. Arnold JH. High-frequency ventilation in the pediatric intensive care unit. Pediatr Crit Care Med 2000;1:93-9.

10. Derdak S, Mehta S, Stewart TE, et al. High-frequency oscillatory ventilation for acute respiratory distress syndrome in adults: a randomized, controlled trial. Am J Respir Crit Care Med 2002;166:801-8.

11. Bollen CW, van Well GT, Sherry T, et al. High frequency oscillatory ventilation compared with conventional mechanical ventilation in adult respiratory distress syndrome: a randomized controlled trial [ISRCTN24242669]. Crit Care 2005;9:R430-9.

12. Mentzelopoulos SD, Malachias S, Zintzaras E, et al. Intermittent recruitment with high-frequency oscillation/ tracheal gas insufflation in acute respiratory distress syndrome. Eur Respir J 2012;39:635-47.

13. Young D, Lamb SE, Shah S, et al. High-frequency oscillation for acute respiratory distress syndrome. $\mathrm{N}$ Engl J Med 2013;368:806-13.

14. Ferguson ND, Slutsky AS, Meade MO. High-frequency oscillation for ARDS. N Engl J Med 2013;368:2233-4.
15. Fort P, Farmer C, Westerman J, et al. High-frequency oscillatory ventilation for adult respiratory distress syndrome--a pilot study. Crit Care Med 1997;25:937-47.

16. Mehta S, Granton J, MacDonald RJ, et al. High-frequency oscillatory ventilation in adults: the Toronto experience. Chest 2004;126:518-27.

17. Sud S, Sud M, Friedrich JO, et al. High frequency oscillation in patients with acute lung injury and acute respiratory distress syndrome (ARDS): systematic review and meta-analysis. BMJ 2010;340:c2327.

18. Sud S, Sud M, Friedrich JO, et al. High-frequency oscillatory ventilation versus conventional ventilation for acute respiratory distress syndrome. Cochrane Database Syst Rev 2016;4:CD004085.

19. Goligher EC, Munshi L, Adhikari NKJ, et al. HighFrequency Oscillation for Adult Patients with Acute Respiratory Distress Syndrome. A Systematic Review and Meta-Analysis. Ann Am Thorac Soc 2017;14:S289-96.

20. Gu XL, Wu GN, Yao YW, et al. Is high-frequency oscillatory ventilation more effective and safer than conventional protective ventilation in adult acute respiratory distress syndrome patients? A meta-analysis of randomized controlled trials. Crit Care 2014;18:R111.

21. Arnold JH, Truog RD, Thompson JE, et al. Highfrequency oscillatory ventilation in pediatric respiratory failure. Crit Care Med 1993;21:272-8.

22. Rosenberg RB, Broner CW, Peters KJ, et al. Highfrequency ventilation for acute pediatric respiratory failure. Chest 1993;104:1216-21.

23. Arnold JH, Hanson JH, Toro-Figuero LO, et al. Prospective, randomized comparison of high-frequency oscillatory ventilation and conventional mechanical ventilation in pediatric respiratory failure. Crit Care Med 1994;22:1530-9.

24. Gupta P, Green JW, Tang X, et al. Comparison of highfrequency oscillatory ventilation and conventional mechanical ventilation in pediatric respiratory failure. JAMA Pediatr 2014;168:243-9.

25. Wong JJ, Liu S, Dang H, et al. The impact of high frequency oscillatory ventilation on mortality in paediatric acute respiratory distress syndrome. Crit Care 2020;24:31.

26. Bateman ST, Borasino S, Asaro LA, et al. Early HighFrequency Oscillatory Ventilation in Pediatric Acute Respiratory Failure. A Propensity Score Analysis. Am J Respir Crit Care Med 2016;193:495-503.

27. de Jager P, Kamp T, Dijkstra SK, et al. Feasibility of an alternative, physiologic, individualized open-lung approach to high-frequency oscillatory ventilation in children. Ann 
Intensive Care 2019;9:9.

28. Khemani RG, Smith L, Lopez-Fernandez YM, et al. Paediatric acute respiratory distress syndrome incidence and epidemiology (PARDIE): an international, observational study. Lancet Respir Med 2019;7:115-28.

29. McCulloch PR, Forkert PG, Froese AB. Lung volume maintenance prevents lung injury during high frequency oscillatory ventilation in surfactant-deficient rabbits. Am Rev Respir Dis 1988;137:1185-92.

30. Sugiura M, McCulloch PR, Wren S, et al. Ventilator pattern influences neutrophil influx and activation in atelectasis-prone rabbit lung. J Appl Physiol (1985) 1994;77:1355-65.

31. Kolton M, Cattran CB, Kent G, et al. Oxygenation during high-frequency ventilation compared with conventional mechanical ventilation in two models of lung injury. Anesth Analg 1982;61:323-32.

32. Delemos RA, Coalson JJ, Gerstmann DR, et al. Ventilatory management of infant baboons with hyaline membrane disease: the use of high frequency ventilation. Pediatr Res 1987;21:594-602.

33. Hamilton PP, Onayemi A, Smyth JA, et al. Comparison of conventional and high-frequency ventilation: oxygenation and lung pathology. J Appl Physiol Respir Environ Exerc Physiol 1983;55:131-8.

34. Rotta AT, Gunnarsson B, Fuhrman BP, et al. Comparison of lung protective ventilation strategies in a rabbit model of acute lung injury. Crit Care Med 2001;29:2176-84.

35. Vázquez de Anda GF, Hartog A, Verbrugge SJ, et al. The open lung concept: pressure-controlled ventilation is as effective as high-frequency oscillatory ventilation in improving gas exchange and lung mechanics in surfactantdeficient animals. Intensive Care Med 1999;25:990-6.

36. Pediatric Acute Lung Injury Consensus Conference Group. Pediatric acute respiratory distress syndrome: consensus recommendations from the Pediatric Acute Lung Injury Consensus Conference. Pediatr Crit Care Med 2015;16:428-39.

37. Rimensberger PC, Cheifetz IM; Pediatric Acute Lung Injury Consensus Conference Group. Ventilatory support in children with pediatric acute respiratory distress syndrome: proceedings from the Pediatric Acute Lung Injury Consensus Conference. Pediatr Crit Care Med 2015;16:S51-60.

38. Available online: https://prospect-network.org/

39. Salim A, Martin M. High-frequency percussive ventilation. Crit Care Med 2005;33:S241-5.

40. Rizkalla NA, Dominick CL, Fitzgerald JC, et al. High- frequency percussive ventilation improves oxygenation and ventilation in pediatric patients with acute respiratory failure. J Crit Care 2014;29:314.e1-7.

41. Tawfik DS, Bennett TD, Welch B, et al. Use of HighFrequency Ventilation in the Pediatric Intensive Care Unit. J Pediatr Intensive Care 2016;5:12-20.

42. Paviotti G, Bua J, De Cunto A, et al. High-frequency percussive ventilation as rescue treatment in severe hypoxemic respiratory failure in term neonates. J Crit Care 2014;29:662-3.

43. Mabe TG, Honeycutt T, Cairns BA, et al. Highfrequency percussive ventilation in a pediatric patient with hydrocarbon aspiration. Pediatr Crit Care Med 2007;8:383-5.

44. Fitzgerald JC, Topjian AA, McInnes AD, et al. Bi-caval dual lumen venovenous extracorporeal membrane oxygenation and high-frequency percussive ventilatory support for postintubation tracheal injury and acute respiratory distress syndrome. J Pediatr Surg 2011;46:e11-5.

45. Claudet I, Marcoux MO, Karsenty C, et al. Severe hydrogen sulfide intoxication: a pediatric case of survival. Ann Fr Anesth Reanim 2012;31:255-8.

46. Blondonnet R, Aliane J, Godet T, et al. High-frequency percussive ventilation as a rescue therapy for ARDS patients under ECMO: About a case. Anaesth Crit Care Pain Med 2015;34:105-7.

47. Miller AC, Ferrada PA, Kadri SS, et al. High-Frequency Ventilation Modalities as Salvage Therapy for Smoke Inhalation-Associated Acute Lung Injury: A Systematic Review. J Intensive Care Med 2018;33:335-45.

48. Yehya N, Dominick CL, Connelly JT, et al. Highfrequency percussive ventilation and bronchoscopy during extracorporeal life support in children. ASAIO J 2014;60:424-8.

49. Wang D, Zwischenberger JB, Savage C, et al. Highfrequency percussive ventilation with systemic heparin improves short-term survival in a LD100 sheep model of acute respiratory distress syndrome. J Burn Care Res 2006;27:463-71.

50. Schmalstieg FC, Keeney SE, Rudloff HE, et al. Arteriovenous CO2 removal improves survival compared to high frequency percussive and low tidal volume ventilation in a smoke/burn sheep acute respiratory distress syndrome model. Ann Surg 2007;246:512-21; discussion 21-3.

51. Dutta R, Xing T, Murdoch GK. Comparison of pressure, volume and gas washout characteristics between PCV and HFPV in healthy and formalin fixed ex vivo porcine lungs. Physiol Meas 2018;39:095003. 
52. Allardet-Servent J, Bregeon F, Delpierre S, et al. Highfrequency percussive ventilation attenuates lung injury in a rabbit model of gastric juice aspiration. Intensive Care Med 2008;34:91-100.

53. Yershov AL, Jordan BS, Fudge JM, et al. Influence of the mode of ventilation on ketamine/xylazine requirements in rabbits. Vet Anaesth Analg 2007;34:157-63.

54. Lucangelo U, Antonaglia V, Zin WA, et al. Mechanical loads modulate tidal volume and lung washout during high-frequency percussive ventilation. Respir Physiol Neurobiol 2006;150:44-51.

55. Allan PF, Naworol G. Corrective measures for compromised oxygen delivery during endotracheal tube cuff deflation with high-frequency percussive ventilation. Respir Care 2007;52:271-7.

56. Allan PF, Thurlby JR, Naworol GA. Measurement of pulsatile tidal volume, pressure amplitude, and gas flow during high-frequency percussive ventilation, with and without partial cuff deflation. Respir Care 2007;52:45-9.

57. Allan PF, Hollingsworth MJ, Maniere GC, et al. Airway humidification during high-frequency percussive ventilation. Respir Care 2009;54:350-8.

58. Lucangelo U, Accardo A, Bernardi A, et al. Gas distribution in a two-compartment model ventilated in high-frequency percussive and pressure-controlled modes. Intensive Care Med 2010;36:2125-31.

59. Allan PF. High-frequency percussive ventilation: pneumotachograph validation and tidal volume analysis. Respir Care 2010;55:734-40.

60. Riscica F, Lucangelo U, Accardo A. Portable instrument for the volume measurement of high-frequency percussive ventilators - biomed 2010. Biomed Sci Instrum 2010;46:93-8.

61. Riscica F, Lucangelo U, Ferluga M, et al. In vitro measurements of respiratory mechanics during HFPV using a mechanical lung model. Physiol Meas 2011;32:637-48.

62. Branson RD, Griebel J, Rodriquez D, Jr. A bench study of inhaled nitric oxide delivery during high frequency percussive ventilation. Pediatr Pulmonol 2018;53:337-41.

63. Chatburn RL, Carlo WA, Primiano FP. Airway-Pressure Measurement during High Frequency Ventilation. Respir Care 1985;30:750-8.

64. Krishnan JA, Brower RG. High-frequency ventilation for acute lung injury and ARDS. Chest 2000;118:795-807.

65. Ethawi YH, Abou Mehrem A, Minski J, et al. High frequency jet ventilation versus high frequency oscillatory ventilation for pulmonary dysfunction in preterm infants. Cochrane Database Syst Rev 2016;2016:CD010548.
66. Rojas-Reyes MX, Orrego-Rojas PA. Rescue highfrequency jet ventilation versus conventional ventilation for severe pulmonary dysfunction in preterm infants. Cochrane Database Syst Rev 2015;2015:CD000437.

67. Miller AG, Haynes KE, Gates RM, et al. High-Frequency Jet Ventilation in Pediatric Acute Respiratory Failure. Respir Care 2020. [Epub ahead of print].

68. Valentine KM, Sarnaik AA, Sandhu HS, et al. High Frequency Jet Ventilation in Respiratory Failure Secondary to Respiratory Syncytial Virus Infection: A Case Series. Front Pediatr 2016;4:92.

69. Smith DW, Frankel LR, Derish MT, et al. High-frequency jet ventilation in children with the adult respiratory distress syndrome complicated by pulmonary barotrauma. Pediatr Pulmonol 1993;15:279-86.

70. Zhang Q, Macartney J, Sampaio L, et al. High Frequency Jet Ventilation during Initial Management, Stabilization, and Transport of Newborn Infants with Congenital Diaphragmatic Hernia: A Case Series. Crit Care Res Pract 2013;2013:937871.

71. Kuluz MA, Smith PB, Mears SP, et al. Preliminary observations of the use of high-frequency jet ventilation as rescue therapy in infants with congenital diaphragmatic hernia. J Pediatr Surg 2010;45:698-702.

72. Gupta VK, Grayck EN, Cheifetz IM. Heliox administration during high-frequency jet ventilation augments carbon dioxide clearance. Respir Care 2004;49:1038-44.

73. Kocis KC, Meliones JN, Dekeon MK, et al. Highfrequency jet ventilation for respiratory failure after congenital heart surgery. Circulation 1992;86:II127-32.

74. Meliones JN, Bove EL, Dekeon MK, et al. Highfrequency jet ventilation improves cardiac function after the Fontan procedure. Circulation 1991;84:III364-8.

75. Vincent RN, Stark AR, Lang P, et al. Hemodynamic response to high-frequency ventilation in infants following cardiac surgery. Pediatrics 1984;73:426-30.

76. Weiner JH, Chatburn RL, Carlo WA. Ventilatory and Hemodynamic Effects of High-Frequency Jet Ventilation following Cardiac Surgery. Respir Care 1987;32:332-8.

77. Zobel G, Dacar D, Rodl S. Proximal and tracheal airway pressures during different modes of mechanical ventilation: an animal model study. Pediatr Pulmonol 1994;18:239-43.

78. Pérez Fontán JJ, Heldt GP, Gregory GA. Mean airway pressure and mean alveolar pressure during highfrequency jet ventilation in rabbits. J Appl Physiol (1985) 1986;61:456-63.

79. Boros SJ, Mammel MC, Coleman JM, et al. Comparison 
of high-frequency oscillatory ventilation and highfrequency jet ventilation in cats with normal lungs. Pediatr Pulmonol 1989;7:35-41.

80. Sood BG, Latif Z, Shen Y, et al. Aerosol delivery during high frequency jet ventilation: an MRI evaluation. Respir Care 2012;57:1901-7.

81. Bass AL, Gentile MA, Heinz JP, et al. Setting positive endexpiratory pressure during jet ventilation to replicate the mean airway pressure of oscillatory ventilation. Respir Care 2007;52:50-5.

82. Downs JB, Stock MC. Airway pressure release ventilation: a new concept in ventilatory support. Crit Care Med 1987;15:459-61.

83. Stock MC, Downs JB, Frolicher DA. Airway pressure release ventilation. Crit Care Med 1987;15:462-6.

84. Daoud EG, Farag HL, Chatburn RL. Airway pressure release ventilation: what do we know? Respir Care 2012;57:282-92.

85. Putensen C, Wrigge H. Clinical review: biphasic positive airway pressure and airway pressure release ventilation. Crit Care 2004;8:492-7.

86. Habashi NM. Other approaches to open-lung ventilation: airway pressure release ventilation. Crit Care Med 2005;33:S228-40.

87. Venkataraman S, Kinsella JP. Airway Pressure Release Ventilation: A Therapy in Search of a Disease? Am J Respir Crit Care Med 2018;198:1118-9.

88. Jain SV, Kollisch-Singule M, Sadowitz B, et al. The 30year evolution of airway pressure release ventilation (APRV). Intensive Care Med Exp 2016;4:11.

89. Mireles-Cabodevila E, Kacmarek RM. Should Airway Pressure Release Ventilation Be the Primary Mode in ARDS? Respir Care 2016;61:761-73.

90. Carsetti A, Damiani E, Domizi R, et al. Airway pressure release ventilation during acute hypoxemic respiratory failure: a systematic review and meta-analysis of randomized controlled trials. Ann Intensive Care 2019;9:44.

91. Miller AG, Gentile MA, Davies JD, et al. Clinical Management Strategies for Airway Pressure Release Ventilation: A Survey of Clinical Practice. Respir Care 2017;62:1264-8.

92. Rose L, Hawkins M. Airway pressure release ventilation and biphasic positive airway pressure: a systematic review of definitional criteria. Intensive Care Med 2008;34:1766-73.

93. Chandelia S, Jain S. Severe Pediatric Acute Respiratory Distress Syndrome Due to Scrub Typhus: Successful Ventilation with Airway Pressure Release Ventilation
Mode after Becoming Refractory to Protective Ventilation. Indian J Crit Care Med 2017;21:326-8.

94. Demirkol D, Karabocuoglu M, Citak A. Airway pressure release ventilation: an alternative ventilation mode for pediatric acute hypoxemic respiratory failure. Indian J Pediatr 2010;77:1322-5.

95. Kamath SS, Super DM, Mhanna MJ. Effects of airway pressure release ventilation on blood pressure and urine output in children. Pediatr Pulmonol 2010;45:48-54.

96. Kawaguchi A, Guerra GG, Duff JP, et al. Hemodynamic changes in child acute respiratory distress syndrome with airway pressure release ventilation: a case series. Clin Respir J 2015;9:423-9.

97. Krishnan J, Morrison W. Airway pressure release ventilation: A pediatric case series. Pediatr Pulmonol 2007;42:83-8.

98. Lalgudi Ganesan S, Jayashree M, Chandra Singhi S, et al. Airway Pressure Release Ventilation in Pediatric Acute Respiratory Distress Syndrome. A Randomized Controlled Trial. Am J Respir Crit Care Med 2018;198:1199-207.

99. Schultz TR, Costarino AJA, Durning SM, et al. Airway pressure release ventilation in pediatrics. Pediatr Crit Care Med 2001;2:243-6.

100. Walsh MA, Merat M, La Rotta G, et al. Airway pressure release ventilation improves pulmonary blood flow in infants after cardiac surgery. Crit Care Med 2011;39:2599-604.

101. Yehya N, Topjian AA, Lin R, et al. High frequency oscillation and airway pressure release ventilation in pediatric respiratory failure. Pediatr Pulmonol 2014;49:707-15.

102. Yehya N, Topjian AA, Thomas NJ, et al. Improved oxygenation 24 hours after transition to airway pressure release ventilation or high-frequency oscillatory ventilation accurately discriminates survival in immunocompromised pediatric patients with acute respiratory distress syndrome*. Pediatr Crit Care Med 2014;15:e147-56.

103. Yener N, Üdürgücü $M$. Airway Pressure Release Ventilation as a Rescue Therapy in Pediatric Acute Respiratory Distress Syndrome. Indian J Pediatr 2020;87:905-9.

104.Ning B, Liang L, Lyu Y, et al. The effect of high-frequency oscillatory ventilation or airway pressure release ventilation on children with acute respiratory distress syndrome as a rescue therapy. Transl Pediatr 2020;9:213-20.

105.Davies SW, Leonard KL, Falls RK, Jr., et al. Lung protective ventilation (ARDSNet) versus airway pressure release ventilation: ventilatory management in a combined model of acute lung and brain injury. J Trauma Acute Care 
Surg 2015;78:240-9; discussion 9-51.

106. Kollisch-Singule M, Emr B, Smith B, et al. Mechanical breath profile of airway pressure release ventilation: the effect on alveolar recruitment and microstrain in acute lung injury. JAMA Surg 2014;149:1138-45.

107.Kollisch-Singule M, Emr B, Smith B, et al. Airway pressure release ventilation reduces conducting airway micro-strain in lung injury. J Am Coll Surg 2014;219:968-76.

108. Kollisch-Singule M, Jain S, Andrews P, et al. Effect of Airway Pressure Release Ventilation on Dynamic Alveolar Heterogeneity. JAMA Surg 2016;151:64-72.

109. Mahajan M, DiStefano D, Satalin J, et al. Time-controlled adaptive ventilation (TCAV) accelerates simulated mucus clearance via increased expiratory flow rate. Intensive Care Med Exp 2019;7:27.

110. Matsuzawa Y, Nakazawa K, Yamamura A, et al. Airway pressure release ventilation reduces the increase in bronchoalveolar lavage fluid high-mobility group box1 levels and lung water in experimental acute respiratory distress syndrome induced by lung lavage. Eur $\mathbf{J}$ Anaesthesiol 2010;27:726-33.

111.Hering R, Bolten JC, Kreyer S, et al. Spontaneous breathing during airway pressure release ventilation in experimental lung injury: effects on hepatic blood flow. Intensive Care Med 2008;34:523-7.

112.Hering R, Viehofer A, Zinserling J, et al. Effects of spontaneous breathing during airway pressure release ventilation on intestinal blood flow in experimental lung injury. Anesthesiology 2003;99:1137-44.

113.Hering R, Peters D, Zinserling J, et al. Effects of spontaneous breathing during airway pressure release ventilation on renal perfusion and function in patients with acute lung injury. Intensive Care Med 2002;28:1426-33.

114. Kreyer S, Putensen C, Berg A, et al. Effects of spontaneous breathing during airway pressure release ventilation on cerebral and spinal cord perfusion in experimental acute lung injury. J Neurosurg Anesthesiol 2010;22:323-9.

115. Carvalho NC, Güldner A, Beda A, et al. Higher levels of spontaneous breathing reduce lung injury in experimental moderate acute respiratory distress syndrome. Crit Care Med 2014;42:e702-15.

116.Emr B, Gatto LA, Roy S, et al. Airway pressure release ventilation prevents ventilator-induced lung injury in normal lungs. JAMA Surg 2013;148:1005-12.

117. Roy S, Sadowitz B, Andrews P, et al. Early stabilizing alveolar ventilation prevents acute respiratory distress syndrome: a novel timing-based ventilatory intervention to avert lung injury. J Trauma Acute Care Surg
2012;73:391-400.

118. Roy S, Habashi N, Sadowitz B, et al. Early airway pressure release ventilation prevents ARDS-a novel preventive approach to lung injury. Shock 2013;39:28-38.

119. Roy SK, Emr B, Sadowitz B, et al. Preemptive application of airway pressure release ventilation prevents development of acute respiratory distress syndrome in a rat traumatic hemorrhagic shock model. Shock 2013;40:210-6.

120. Sasidhar M, Chatburn RL. Tidal volume variability during airway pressure release ventilation: case summary and theoretical analysis. Respir Care 2012;57:1325-33.

121. Chatburn RL, Kallet RH, Sasidhar M. Airway Pressure Release Ventilation May Result in Occult Atelectrauma in Severe ARDS. Respir Care 2016;61:1278-80.

122.Perinel-Ragey S, Baboi L, Guerin C. Variability of Tidal Volume in Patient-Triggered Mechanical Ventilation in ARDS. Respir Care 2017;62:1437-46.

123. Richard JC, Lyazidi A, Akoumianaki E, et al. Potentially harmful effects of inspiratory synchronization during pressure preset ventilation. Intensive Care Med 2013;39:2003-10.

124.Ge HQ, Wang JM, Lin HL, et al. Effect of Nebulizer Location and Spontaneous Breathing on Aerosol Delivery During Airway Pressure Release Ventilation in Bench Testing. J Aerosol Med Pulm Drug Deliv 2019;32:34-9.

125. Daoud EG, Chatburn RL. Comparing surrogates of oxygenation and ventilation between airway pressure release ventilation and biphasic airway pressure in a mechanical model of adult respiratory distress syndrome. Respir Investig 2014;52:236-41.

126. Yoshida T, Uchiyama A, Mashimo T, et al. The effect of ventilator performance on airway pressure release ventilation: a model lung study. Anesth Analg 2011;113:529-33.

127. Sinderby C, Navalesi P, Beck J, et al. Neural control of mechanical ventilation in respiratory failure. Nat Med 1999;5:1433-6.

128. Beck J, Brander L, Slutsky AS, et al. Non-invasive neurally adjusted ventilatory assist in rabbits with acute lung injury. Intensive Care Med 2008;34:316-23.

129. Barwing J, Ambold M, Linden N, et al. Evaluation of the catheter positioning for neurally adjusted ventilatory assist. Intensive Care Med 2009;35:1809-14.

130. Barwing J, Pedroni C, Quintel M, et al. Influence of body position, PEEP and intra-abdominal pressure on the catheter positioning for neurally adjusted ventilatory assist. Intensive Care Med 2011;37:2041-5.

131.Karikari S, Rausa J, Flores S, et al. Neurally adjusted 
ventilatory assist versus conventional ventilation in the pediatric population: Are there benefits? Pediatr Pulmonol 2019;54:1374-81.

132. Kacmarek RM, Villar J, Parrilla D, et al. Neurally adjusted ventilatory assist in acute respiratory failure: a randomized controlled trial. Intensive Care Med 2020;46:2327-37.

133. Hadfield DJ, Rose L, Reid F, et al. Neurally adjusted ventilatory assist versus pressure support ventilation: a randomized controlled feasibility trial performed in patients at risk of prolonged mechanical ventilation. Crit Care 2020;24:220.

134. Bengtsson JA, Edberg KE. Neurally adjusted ventilatory assist in children: An observational study. Pediatr Crit Care Med 2010;11:253-7.

135. Breatnach C, Conlon NP, Stack M, et al. A prospective crossover comparison of neurally adjusted ventilatory assist and pressure-support ventilation in a pediatric and neonatal intensive care unit population. Pediatr Crit Care Med 2010;11:7-11.

136. Bordessoule A, Emeriaud G, Morneau S, et al. Neurally adjusted ventilatory assist improves patient-ventilator interaction in infants as compared with conventional ventilation. Pediatr Res 2012;72:194-202.

137.Ålander M, Peltoniemi O, Pokka T, et al. Comparison of pressure-, flow-, and NAVA-Triggering in pediatric and neonatal ventilatory care. Pediatric Pulmonology 2012;47:76-83.

138. de la Oliva P, Schüffelmann C, Gómez-Zamora A, et al. Asynchrony, neural drive, ventilatory variability and COMFORT: NAVA versus pressure support in pediatric patients. A non-randomized cross-over trial. Intensive Care Med 2012;38:838-46.

139. Mortamet G, Larouche A, Ducharme-Crevier L, et al. Patient-ventilator asynchrony during conventional mechanical ventilation in children. Annals of Intensive Care. 2017;7(1):122.

140. Beck J, Emeriaud G, Liu Y, et al. Neurally-adjusted ventilatory assist (NAVA) in children: a systematic review. Minerva Anestesiol 2016;82:874-83.

141.Piastra M, De Luca D, Costa R, et al. Neurally adjusted ventilatory assist vs pressure support ventilation in infants recovering from severe acute respiratory distress syndrome: nested study. J Crit Care 2014;29:312.e1-5.

142.Kallio M, Peltoniemi O, Anttila E, et al. Neurally adjusted ventilatory assist (NAVA) in pediatric intensive care--a randomized controlled trial. Pediatr Pulmonol 2015;50:55-62.

143. Clement KC, Thurman TL, Holt SJ, et al. Neurally triggered breaths reduce trigger delay and improve ventilator response times in ventilated infants with bronchiolitis. Intensive Care Med 2011;37:1826-32.

144. Liet JM, Dejode JM, Joram N, et al. Respiratory support by neurally adjusted ventilatory assist (NAVA) in severe RSV-related bronchiolitis: a case series report. BMC Pediatr 2011;11:92.

145. Spinazzola G, Costa R, De Luca D, et al. Pressure Support Ventilation (PSV) versus Neurally Adjusted Ventilatory Assist (NAVA) in difficult to wean pediatric ARDS patients: a physiologic crossover study. BMC Pediatr 2020;20:334.

146. Baez Hernandez N, Milad A, Li Y, et al. Utilization of Neurally Adjusted Ventilatory Assist (NAVA) Mode in Infants and Children Undergoing Congenital Heart Surgery: A Retrospective Review. Pediatr Cardiol 2019;40:563-9.

147. Crulli B, Khebir M, Toledano B, et al. Neurally Adjusted Ventilatory Assist After Pediatric Cardiac Surgery: Clinical Experience and Impact on Ventilation Pressures. Respir Care 2018;63:208-14.

148.Liet JM, Barriere F, Gaillard-Le Roux B, et al. Physiological effects of invasive ventilation with neurally adjusted ventilatory assist (NAVA) in a crossover study. BMC Pediatr. 2016;16:180.

149.Zhu LM, Shi ZY, Ji G, et al. Application of neurally adjusted ventilatory assist in infants who underwent cardiac surgery for congenital heart disease. Zhongguo Dang Dai Er Ke Za Zhi 2009;11:433-6.

150. Bonacina D, Bronco A, Nacoti M, et al. Pressure support ventilation, sigh adjunct to pressure support ventilation, and neurally adjusted ventilatory assist in infants after cardiac surgery: A physiologic crossover randomized study. Pediatr Pulmonol 2019;54:1078-86.

151.Assy J, Mauriat P, Tafer N, et al. Neurally adjusted ventilatory assist for children on veno-venous ECMO. J Artif Organs 2019;22:118-25.

152. Brander L, Sinderby C, Lecomte F, et al. Neurally adjusted ventilatory assist decreases ventilator-induced lung injury and non-pulmonary organ dysfunction in rabbits with acute lung injury. Intensive Care Med 2009;35:1979-89.

153. Beck J, Campoccia F, Allo JC, et al. Improved synchrony and respiratory unloading by neurally adjusted ventilatory assist (NAVA) in lung-injured rabbits. Pediatr Res 2007;61:289-94.

154. Campoccia Jalde F, Almadhoob AR, Beck J, et al. Neurally adjusted ventilatory assist and pressure support ventilation in small species and the impact of instrumental dead space. Neonatology 2010;97:279-85. 
155.Heulitt MJ, Clement KC, Holt SJ, et al. Neurally triggered breaths have reduced response time, work of breathing, and asynchrony compared with pneumatically triggered breaths in a recovering animal model of lung injury. Pediatr Crit Care Med 2012;13:e195-203.

156.Allo JC, Beck JC, Brander L, et al. Influence of neurally adjusted ventilatory assist and positive end-expiratory pressure on breathing pattern in rabbits with acute lung injury. Crit Care Med 2006;34:2997-3004.

157.Liu L, Takahashi D, Qui H, et al. Feasibility of neurally adjusted positive end-expiratory pressure in rabbits with early experimental lung injury. BMC Anesthesiol 2015;15:124.

Cite this article as: Miller AG, Bartle RM, Feldman A, Mallory P, Reyes E, Scott B, Rotta AT. A narrative review of advanced ventilator modes in the pediatric intensive care unit. Transl Pediatr 2021;10(10):2700-2719. doi: 10.21037/tp-20-332
158. Takahashi D, Liu L, Sinderby C, et al. Feasibility of neurally synchronized and proportional negative pressure ventilation in a small animal model. Physiol Rep 2020;8:e14499.

159. Widing CH, Pellegrini M, Larsson A, et al. The Effects of Positive End-Expiratory Pressure on Transpulmonary Pressure and Recruitment-Derecruitment During Neurally Adjusted Ventilator Assist: A Continuous Computed Tomography Study in an Animal Model of Acute Respiratory Distress Syndrome. Front Physiol 2019;10:1392.

160. Shimatani T, Shime N, Nakamura T, et al. Neurally adjusted ventilatory assist mitigates ventilator-induced diaphragm injury in rabbits. Respir Res 2019;20:293. 